\title{
Implementasi Metode Ekstraksi Fitur Gabor Filter dan Probablity Neural Network (PNN) untuk Identifikasi Kain Tapis Lampung
}

\author{
${ }^{1}$ Admi Syarif, ${ }^{2}$ Akbar R. Tanjung, ${ }^{3}$ Rico Andrian dan ${ }^{4}$ Favorisen R. Lumbanraja \\ 1,2,3,4 Jurusan Ilmu Komputer, Fakultas Matematika dan Ilmu Pengetahuan Alam, \\ Universitas Lampung, Lampung, Indonesia \\ email : admi.syarif@fmipa.unila.ac.id
}

\begin{abstract}
Tapis Fabric is a traditional clothing of the people of Lampung in the form of a shawl cloth or a sarong made of woven cotton thread with various motifs and ornaments, silver thread or gold thread by embroidered or punched. The pattern of filter cloth is quite complex, unlike the pattern of fabric in general, with its own uniqueness that has become the culture of Lampung society until now. This filter cloth will be investigated by identifying the three types of filter cloth, namely Sasab, Bintang Perak and Gunung Beradu and see the results of its identification. The method used to identify is by combining the Gabor Filter feature extraction method which has frequency and orientation parameters and Probability Neural Network classification methods. Previously, the combination of these two methods was used to identify objects with simple patterns. The results are quite good, such as detecting faces, leaf patterns, and other simple patterns. This research is expected to get maximum identification results on the filter cloth even though it has a pattern that is not simple and will be used as a research report to determine the suitability of the method used for the filter object.
\end{abstract}

Keywords: Kain Tapis; Lampung; Gabor Filter; Image Processing; Probability Neural Network (PNN)

\section{PENDAHULUAN}

Lampung merupakan Provinsi yang terletak di ujung selatan pulau Sumatra. Provinsi Lampung yang berdiri pada tahun 1964 ini dikenal sebagai Provinsi yang memiliki kekayaan alam, bahasa dan budaya. Salah satu kekayaan budayanya yang cukup dikenal hingga ke manca negara adalah Kain Tapis. Kain Tapis bagi Masyarakat Adat Lampung memiliki makna simbolis sebagai lambang kesucian yang dapat melindungi pemakainya dari segala kotoran dari luar [1]. Kain tapis merupakan pakaian tradisional masyarakat Lampung yang biasa digunakan pada berbagai acara formal dan adat istiadat seperti perkawinan, dan acara-acara sakral lainnya.

Kain tapis pada umumnya merupakan kain tenun yang terbuat dari benang kapas dengan berbagai jenis motif dan biasa dipakai oleh kaum wanita suku Lampung yang berbentuk sarung. Berbagai jenis Kain Tapis Lampung memiliki corak yang berbeda-beda terbagi atas masing-masing wilayah daerah [2].
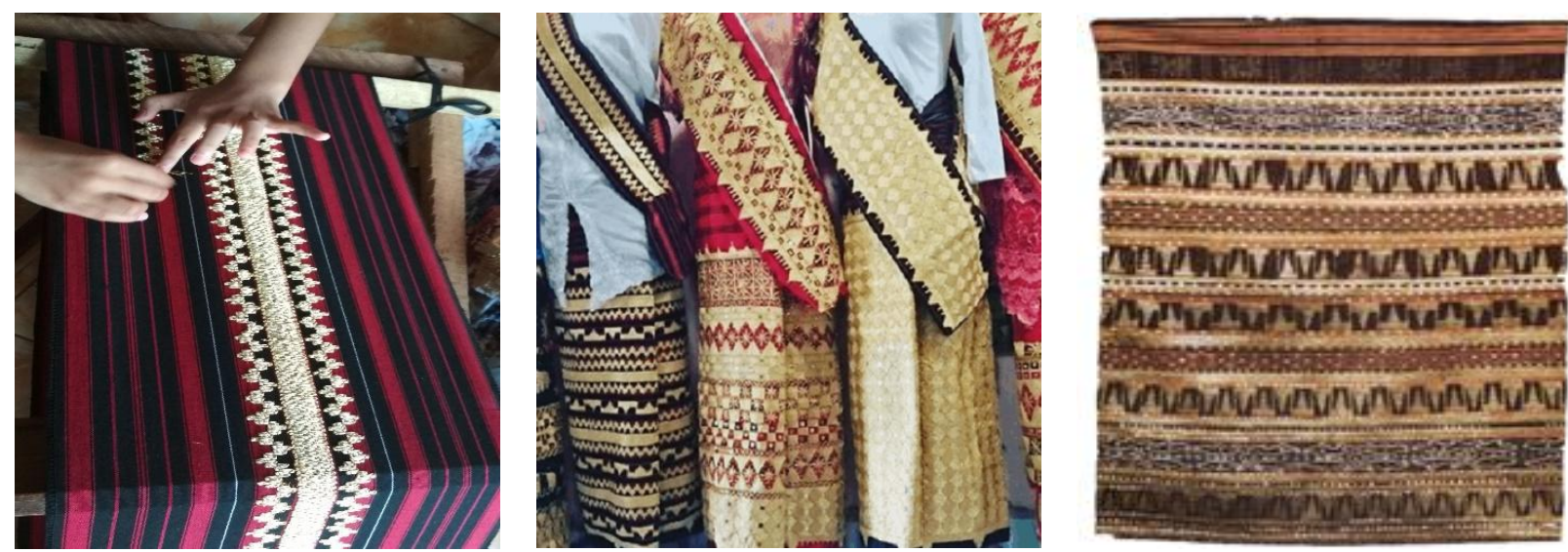

Gambar 1. Ilustrasi Kain Tapis Lampung. 
Wilayah pesisir misal terdapat berbagai jenis Tapis diantaranya yaitu Tapis Inuh, Cucuk Andak, Semaka, Kuning, Cukkil, dan Jinggu juga pada wilayah Pepadun seperti Tapis Rajo Tunggal, Jung Sarat, Linau, Raja Medal, Pucuk Rebung, Tuho, Kaco, Balak dan lainnya. Kain tapis memiliki beraneka ragam motif diantaranya motif alam, flora, dan fauna, motif kait, kunci, gunung, bulan, bintang dan lain-lain. Motif-motif pada Kain Tapis disulam dan dicucuk dengan benang emas atau perak. Motif kain tapis bertujuan untuk memperindah kain. Motif kain tapis dapat dikenali melalui ciri-ciri fisiknya juga oleh pemakainya [3]. Tapis sendiri merupakan salah satu budaya tradisional masyarakat Lampung yang sudah langka, masyarakat pengrajin Tapis hanya membuat motif sesuai pesanan pembeli. Kurangnya kepedulian dan pengetahuan masyarakat Lampung akan budaya Tapis dapat memperburuk keadaan ini. Diperlukan sebuah upaya untuk mendokumentasikan, menginventarisasi, dan melindungi Tapis Lampung[4].

Hadirnya teknologi komputer telah membantu menyelesikan berbagai persoalan dunia nyata dibidang teknik, ekonomi, dan kesehatan dalam beberapa dekade terakhir. Salah satu persoalan yang menarik adalah perkembangan teknik pengolahan citra terutama pada pengolahan gambar. Persoalan ini banyak digunakanan pada beberapa aplikasi khususnya untuk Pengenalan Obyek, Pelacakan Target, konten berbasis pengambilan gambar dan Pengolahan Citra. Teknik pengolahan citra pada bidang ilmu komputer bertujuan untuk memperbaiki kualitas citra agar mudah diinterpretasi oleh manusia atau mesin [5]. Secara keseluruhan pengolahan citra merupakan suatu cara mengusahakan suatu citra menjadi citra lain yang lebih sempurna atau yang diinginkan dengan masukan citra dan menghasilkan keluaran berupa citra seperti yang dikehendaki [6]. Perkembangan teknologi dibidang image processing pada objek kain telah banyak dilakukan, ini menunjukan bahwa metode image processing mampu untuk melakukan proses evaluasi visual terhadap objek kain [7]. Teknik pengolahan citra diharapkan dapat membantu upaya pelestarian budaya kain Tapis Lampung.

Metode ekstraksi ciri Gabor Filter salah satu metode pengolahan citra yang cukup dikenal. Metode ini pertama kali diperkenalkan oleh Denis Gabor pada tahun 1946 [8]. Metode ini merupakan filter linier yang cocok digunakan untuk mendeteksi citra. Cara kerja metode ini mirip dengan sistem visualisasi manusia [9]. Metode ini telah diaplikasikan dalam mengidentifikasi berbagai citra biometrik seperti pola wajah, sidik jari, telapak tangan, dan iris mata [10]. Penelitian sebelumnya menggunakan metode Gabor Filter telah dilakukan terhadap obyek Kain Songket hasilnya didapati bahwa konsumen dapat menentukan pilihan Kain Songket dengan kualitas terbaik [11]. Metode penelitian ini akan diimplementasikan untuk mengenali obyek Kain Tapis.

Secara spasial, fungsi Gabor adalah Gaussian kernel yang dimodulasi oleh gelombang bidang Sinusoidal:

$$
\begin{aligned}
& g(x, y)=w(x, y) s(x, y)=\mathrm{e}^{-\left(\alpha^{2} x^{\prime 2} \beta^{2} y^{\prime 2}\right)} e^{j 2 \pi f x^{\prime}} . \\
\text { dengan } & -x^{\prime}=x \cos \theta+y \sin \theta \\
- & y^{\prime}=-x \sin \theta+y \cos \theta
\end{aligned}
$$

$f$ adalah frekuensi pusat dari gelombang sinus $\theta$ adalah orientasi dari Gaussian dan gelombang. $\alpha$ adalah ketajaman aksis mayor fungsi Gaussian dan $\beta$ adalah ketajaman aksis minor fungsi Gaussian [12]. Menjaga rasio antara frekuensi dan ketajaman konstan maka $\gamma=\frac{f}{\alpha}$ dan $\eta=\frac{f}{\beta}$ didefinisikan gabor filter dapat dirumuskan :

$$
\varphi(x, y)=\frac{f^{2}}{\pi \gamma \eta} g(x, y)=\frac{f^{2}}{\pi \gamma \eta} \mathrm{e}^{-\left(\alpha^{2} x^{\prime 2} \beta^{2} y^{\prime 2}\right)} e^{j 2 \pi f x^{\prime}}
$$

Pembentukan filter Gabor yang didapat selanjutnya dilakukan pembentukan ekstraksi ciri:

$$
O_{\pi(f, \theta, \gamma, \eta)}(x, y)=I(x, y)^{*} \varphi_{\pi(f, \theta, \gamma, \eta)}(x, y)
$$

Perbedaan skala dan orientasi yang digunakan pada Gabor Filter dengan skala 5 dan orientasi 8 untuk ekstraksi fitur :

$$
f_{u}=\frac{f_{\max }}{\sqrt{2^{u}}}, \theta_{v}=\frac{v}{8} \pi, u=\{0, \ldots, 4\}, v=\{0, \ldots, 7\}
$$

Selanjutnya dihasilkan konvolusi input image I $(x, y)$ dengan total 40 Gabor filter :

$$
\mathrm{S}=\left\{O_{u, v}(x, y): u \in\{0, \ldots, 4\}, v \in\{0, \ldots, 7\}\right\}
$$


Dimana $O_{u, v}(x, y)=\left|I(x, y)^{*} \varphi_{\pi\left(f_{u}, \theta_{v}, \gamma, \eta\right)}(x, y)\right|$. Seri dari rangkaian baris vektor $O_{u, v}$ akan dikonversi menjadi $O_{u, v}(x, y)$ oleh penggabungan baris dan kolom untuk menghasilkan diskriminatif vektor Gabor Filter:

$$
G(I)=O=\left(O_{0,0}, O_{0,1}, \ldots, O_{4,7}\right)
$$

Contoh citra dengan ukuran $64 \times 64$, hasil konvolusi memberikan $64 \times 64 \times 5 \times 8=163,840$ fitur Gabor.

Impelmentasi Gabor Filter sebelumnya telah dilakukan oleh Jing J, Xiaoting Fan, dan Fengfei Li mereka menggabungkan antra metode ekstraksi Fitur Gabor Filter dan Kernel Principal Component Analysis (KPCA), objek yang didapati yaitu penelitian terhadap identifikasi kain seragam dan kecacatan tekstur. Perpaduan metode Gabor Filter dan KPCA telah digunakan untuk pengurangan dimensi nonlinier untuk mendeteksi cacat kain yang lebih akurat dan pada akhirnya jenis jenis benang cacat telah ditemukan. Hasil eksperimen itu menunjukan nilai akurasi kecacatan kain sampai $96 \%$ presentase ini cukup memuaskan dan menjanjkain namun diharapkan agar terus dikembangkan dimasa yang akan datang [13].

Keunggulan dari Gabor Filter yaitu mampu mengidentifikasi citra dengan sangat baik juga metode ini banyak digunakan dalam mengekstraksi ciri biometrik. Salah satunya terhadap identifikasi wajah manusia Gabor Filter mampu bekerja dengan sangat baik dalam hal mengklasifikan wajah manusia.

Gabor Filter mampu mengeliminasi parameter variabilitas wajah yang pada metode lainnya sering menggangggu dalam proses pengenalan [14].

Proses klasifikasi dilakukan setelah proses ekstraksi ciri. Metode klasifikasi yang cukup dikenal yaitu Probability Neural Network (PNN). Metode ini merupakan bagian terpenting untuk identifikasi pengelompokan citra. Pengolahan citra dilakukan untuk meningkatkan kualitas citra. Klasifikasi pada pengolahan citra dilakukan dengan masukan (input) berupa citra (image) dan hasilnya (output) juga berupa image.

PNN diperkenalkan oleh Donald Specht pada tahun 1990 sebagai alternatif dari back-propagation neural network [15]. PNN salah satu jaringan neural yang umum digunakan untuk memecahkan permasalahan klasifikasi pola dan metode pelatihan yang sederhana.

PNN terdiri dari empat lapisan yaitu :

1. Lapisan masukan (input layer)

Lapisan masukan merupakan masukan x yang terdiri atas k nilai ciri yang akan diklasifikasikan pada salah satu kelas dari n kelas.

2. Lapisan pola (pattern layer).

Lapisan pola dilakukan perkalian titik (dot product) antara masukan $x$ dan vektor bobot $x_{i j}$, atau $z_{i}=x . x_{i j}$, $z_{i}$ kemudian dibagi dengan bias $\sigma$ tertentu lalu dimasukkan ke dalam fungsi Parzen, yaitu $\mathrm{g}(\mathrm{x})=e^{-n}$ Dengan demikian, persamaan yang digunakan pada lapisan pola adalah Persamaan 3 berikut:

$$
g(x)=e^{-\frac{\left(x-x_{i j}\right)^{T}\left(x-x_{i j}\right)}{2 \sigma^{2}}}
$$

Dengan $x_{i j}$ menyatakan vektor latih kelas ke- $i$ urutan ke-j.

3. Lapisan penjumlahan (summation layer)

Kategori masing-masing unit pada lapisan ini terhubung dengan kelasnya.

Persamaan yang digunakan pada lapisan ini [16].

$$
p(x)=\frac{1}{(2 \pi)^{\frac{k}{2}} \sigma^{k} t} \sum_{i=1}^{t} e^{\left(-\frac{\left(x-x_{i j}\right)^{T}\left(x-x_{i j}\right)}{2 \sigma^{2}}\right)}
$$

4. Lapisan keluaran (output layer)

Lapisan keputusan, masukan $\mathrm{x}$ akan diklasifikasikan ke kelas I jika nilai $p_{i}(x)$ paling besar dibandingkan kelas lainnya. 


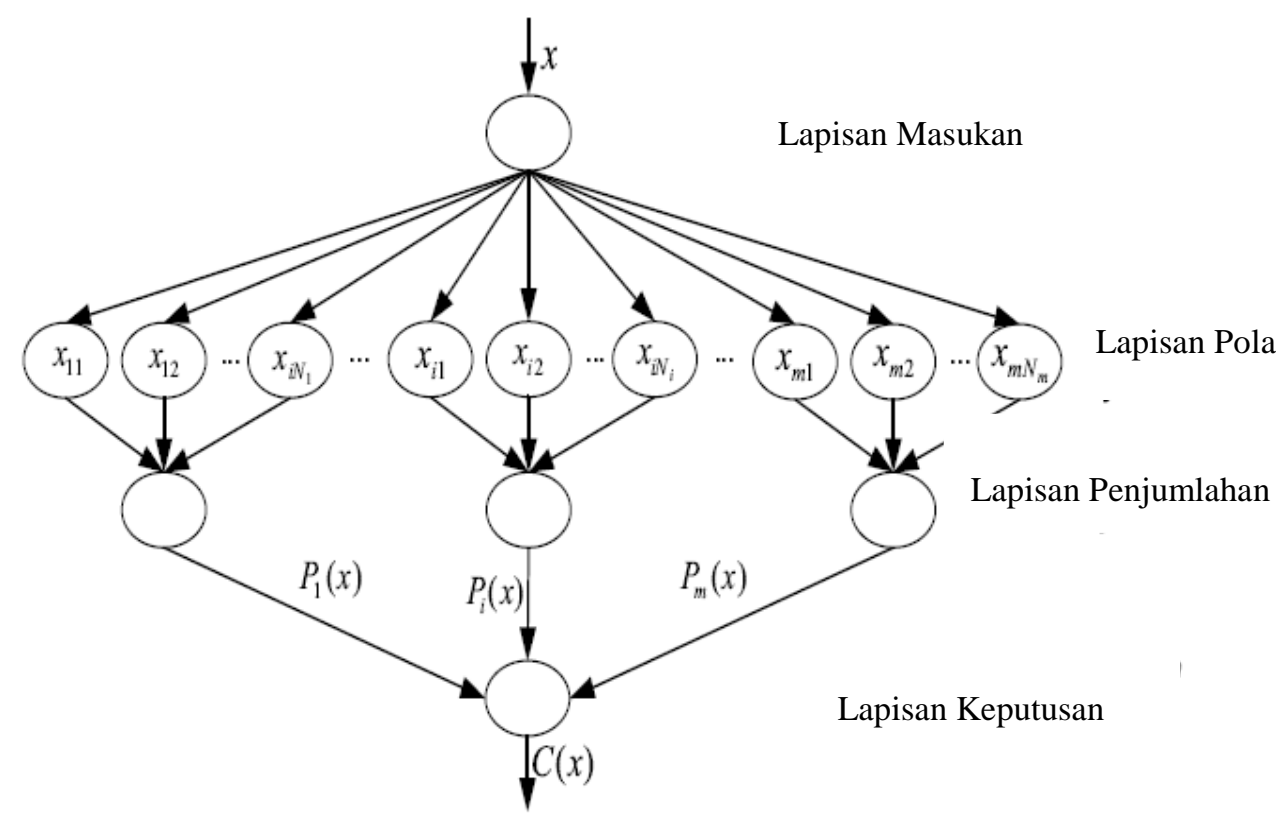

Gambar 2. Arsitektur Probabilistic Neural Network [17].

Keunggulan metode Probability Neural Network ini yaitu dapat mempelajari data pelatihan secara instan, kecepatan ini memberikan kemampuan untuk beradaptasi secara realtime dan dapat menghapus atau menambah data yang baru muncul [18].

Implementasi PNN dengan mengadopsi Field Programmable Gate Arrays (FPGA) telah ditunjukan tangguh untuk identifikasi kecacatan kain [19]. Metode ini dilaporkan mampu mencapai akurasi 98\%, dalam pengujian terhadap kecacatan kain.

Penelitian ini bertujuan untuk mengimplementasikan metode Gabor Filter dan klasifikasi PNN terhadap obyek kain tapis Lampung. Efektifitas metode ini akan dievaluasi menggunakan 525 citra dari 3 (tiga) jenis kain tapis. Untuk setiap jenis kain, citra akan dibagi menjadi 2 (dua) kelompok, yaitu citra latih dan citra uji dengan masing-masing 150 dan 25 buah.

Penulisan ini disusun dengan struktur sebagai berikut : Bagian 1 berisi latar belakang permasalahan penelitian. Bagian 2 menjelaskan proses metode yang diusulkan penelitian dan juga penelitan-penelitian yang dilakukan sebelumnya. Bagian 3 menyajikan metode penelitian, hasil pembahasan, eksperimen, dan evaluasi secara keseluruhan. Kesimpulan diberikan di Bagian 4.

\section{METODOLOGI PENELITIAN}

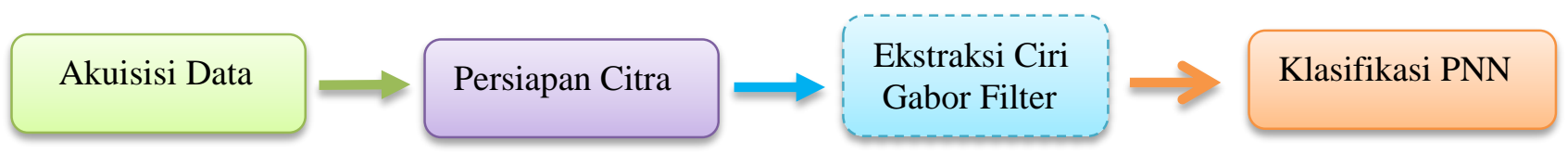

Gambar 3. Tahapan Penelitian. 


\section{Jurnal Komputasi}

\subsection{Akuisisi Data}

Data yang digunakan adalah citra kain jenis Bintang Perak, Sasab, dan Gunung Beradu, dengan total dataset 525 masing-masing jenis kain tapis berjumlah 175 citra. Proses pengambilan citra kain dilakukan menggunakan kamera digital dalam bentuk format JPEG berukuran $2912 \times 5148$ pixel. Pola citra kain tapis Bintang perak, Sasab, dan Gunung Beradu :

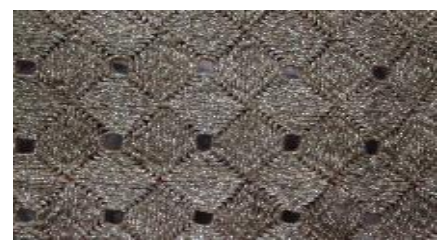

(a). Sasab

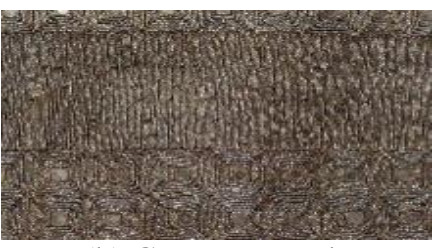

(b).Gunung Beradu

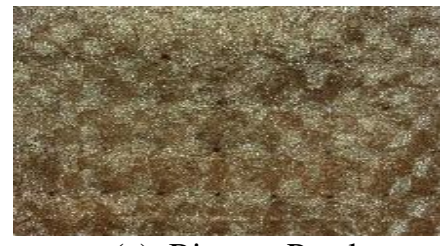

(c). Bintang Perak

Gambar 4. Pola Citra Tapis ( Ukuran $2912 \times 5148$ Pixel ).

\subsection{Persiapan Citra}

Citra tapis yang diambil menggunakan kamera selanjutnya diubah ukuran menjadi $256 \times 256$ pixel menggunakan Corel Draw X7 lalu dilakukan proses perubahan dari citra berwarna RGB (Red, Green, Blue) menjadi Greyscale (skala keabuan).

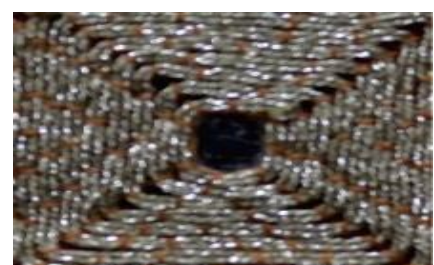

Sasab $(256 \times 256)$

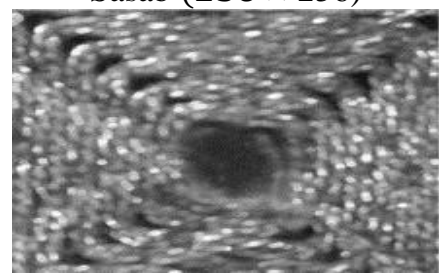

Greyscale $(256 \times 256)$

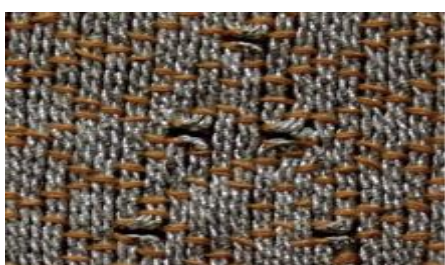

Gunung Beradu $(256 \times 256)$

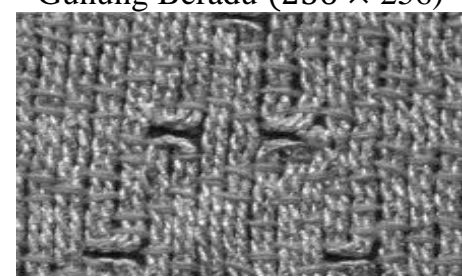

Greyscale $(256 \times 256)$

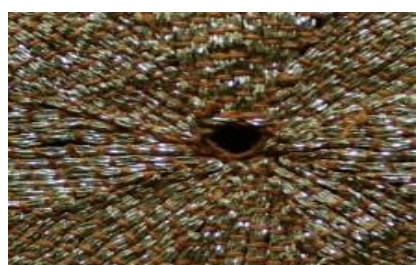

Bintang Perak $(256 \times 256)$

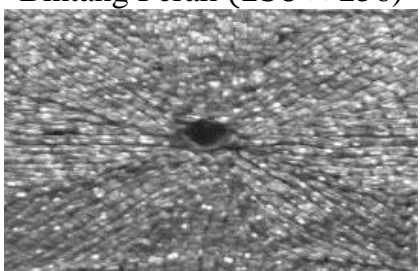

Greyscale $(256 \times 256)$

Gambar 5. Citra Hasil Segmentasi.

\section{3. Ekstraksi Ciri Gabor Filter}

Selanjutnya pengembangan dilakukan menggunakan metode ekstrasksi ciri Gabor Filter. Tahapan awal yaitu menetapkan inisialisasi parameter. Ketetapan parameter memerlukan kombinasi frekuensi, orientasi, ukuran kernel, dan downsample.

Tabel 1. Inisialisasi Parameter.

\begin{tabular}{ccccc}
\hline Jenis Percobaan & Frekuensi & Orientasi & Ukuran Kernel & Downsample \\
\hline Percobaan 1 & 1 & 1 & $(3 \times 3)$ & $(4,4)$ \\
Percobaan 2 & 1 & 2 & $(3 \times 3)$ & $(4,4)$ \\
Percobaan 3 & 2 & 2 & $(3 \times 3)$ & $(4,4)$ \\
\hline
\end{tabular}


Tahapan selanjutnya yaitu pembentukan kernel Gabor dengan bergantung pada nilai frekuensi, orientasi, dan ukuran [20]. Kernel yang telah ditetapkan merujuk pada persamaan (2).

Tabel 2. Nilai Pembentukan Kernel.

\begin{tabular}{|c|l|l|}
\hline \multicolumn{2}{|c|}{ Keterangan } & Nilai \\
\hline $\boldsymbol{f}_{\max }$ & Frekuensi maksimal & 1 \\
\hline $\boldsymbol{\gamma}$ & Gamma & $\sqrt{ } 2$ \\
\hline $\boldsymbol{\eta}$ & Eta & $\sqrt{2}$ \\
\hline $\boldsymbol{f}$ & Total frekunsi & 2 \\
\hline $\boldsymbol{\theta}$ & Total orientasi & 2 \\
\hline $\boldsymbol{x}, \boldsymbol{y}$ & Ukuran kernel yang digunakan & $(1,1)$ \\
\hline $\mathbf{m}, \mathbf{n}$ & Ukuran kernel & $(3,3)$ \\
\hline $\boldsymbol{u}$ & Frekuensi yang digunakan & 1 \\
\hline $\boldsymbol{v}$ & Orientasi yang digunakan & 1 \\
\hline
\end{tabular}

Hasil pembentukan kernel berupa bilangan kompleks yang terdiri dari bagian nilai real dan imaginary. Tahapan berikutnya yaitu proses konvolusi dengan menghitung nilai citra kain dengan nilai kernel yang telah dibentuk. Proses terakhir yaitu pembentukan vektor ciri. Hasil dari konvolusi yaitu milai yang terdiri dari dua bagian nilai real dan imaginary yang akan dinormalisasi.

$$
\operatorname{abs}(x)=\sqrt{\operatorname{real}(x)^{2}+\operatorname{imag}(x)^{2}}
$$

\subsection{Klasifikasi PNN}

Proses berikutnya dilakukan klasifikasi masing-masing jenis kain tapis. Proses klasifikasi dapat dilihat pada Gambar 2 diawali dengan meng-input nilai citra latih kain tapis pada tahapan input layer selanjutnya masuk kedalam tahapan pattern layer mengenali masing-masing nilai kain dan kelasnya, selanjutnya masuk kedalam summation layer sebagai penghubung kategori masing-masing nilai kelas kain yang telah dikelompokkan. Output layer dari hasil proses klasifikasi adalah nilai terbesar dari masing-masing kelas dan jenis kain tapis yang sudah terbagi atas masing-masing kelas. Tahapan terakhir dilakukan evaluasi keseluruhan. Citra uji dianalisis dan diklasifikasikan berdasarkan jenisnya selanjutnya menghitung nilai akurasi dengan persamaan :

$$
\text { Akurasi }=\frac{\text { Citra_uji_benar }}{\text { Citra_latih }} \times 100 \% \text {. }
$$

\section{HASIL DAN PEMBAHASAN}

Hasil klasifikasi Percobaan Tabel P1 dan P2 menunjukkan bahwa kain Sasab dan Gunung Beradu teridentifikasi secara benar sedangkan Bintang Perak mengalami tiga kesalahan identifikasi yang terdeteksi sebagai kain Gunung Beradu. Percobaan Tabel 3 (P3) terlihat beberapa tapis yang tidak terdeteksi dari masingmasing kelas yaitu Bintang perak dua kesalahan identifikasi, Sasab lima kesalahan identifikasi, dan Gunung Beradu empat kesalahan identifikasi. Perhitungan akurasi dilakukan dengan menghitung citra uji yang teridentifikasi dengan benar sesuai masing-masing kelas dibagi dengan total citra yang dilatih lalu hasilnya dikalikan 100 persen. 
Tabel 3. Hasil Rekapitulasi Klasifikasi Kain

\begin{tabular}{|c|c|c|c|c|c|c|c|}
\hline \multirow{3}{*}{ Percobaan } & \multicolumn{6}{|c|}{ Jenis Kain Tapis } & \multirow{3}{*}{$\begin{array}{c}\text { Total Citra } \\
\text { Teridentifikasi }\end{array}$} \\
\hline & \multicolumn{2}{|c|}{ Bintang Perak } & \multicolumn{2}{|c|}{ Gunung Beradu } & \multicolumn{2}{|c|}{ Sasab } & \\
\hline & Benar & Salah & Benar & Salah & Benar & Salah & \\
\hline P1 & 22 & 3 & 25 & 0 & 25 & 0 & 72 \\
\hline $\mathrm{P} 2$ & 22 & 3 & 25 & 0 & 25 & 0 & 72 \\
\hline $\mathrm{P} 3$ & 23 & 2 & 21 & 4 & 20 & 5 & 64 \\
\hline Terbaik & 23 & & 25 & & 25 & & 72 \\
\hline Terburuk & 22 & & 21 & & 20 & & 64 \\
\hline Rata-rata & 23.33 & & 23.66 & & 23.33 & & 69.33 \\
\hline St. Deviasi & 0.57 & & 2.3 & & 2.88 & & 4.07 \\
\hline
\end{tabular}

Identifikasi kain dengan menggunakan ekstraksi fitur Gabor filter dan klasifikasi Probability Neural Network mencapai titik optimum pada Percobaan P1 dan P2. Kombinasi nilai yang digunakan pada Percobaan 3 yang menjadi titik minimum yaitu ukuran kernel $(3,3)$, frekuensi $(2)$ dan, orientasi dan (2) serta nilai downsample $(4,4)$. Penyebab kesalahan identifikasi adalah:

Nilai parameter frekuensi, orientasi, dan ukuran kernel serta downsample mempengaruhi tingkat akurasi. Nilai parameter jika semakin besar yang digunakan, maka semakin banyak variasi vektor ciri yang didapatkan, namun jika variasi vektor ciri terlalu banyak, maka akan menyebabkan redundancy data yang menyebabkan proses klasifikasi menjadi tidak efisien. Kualitas citra yang diakuisisi menjadi terlihat kurang jelas sehingga anatomi pada citra kain kurang terlihat dan membuat fitur ciri kain menjadi mirip serta dianggap sama.

Hasil evaluasi menunjukkan bahwa citra uji terbaik yang terdeteksi dengan benar berjumlah 72 citra kain, terdiri dari 22 citra bintang perak 25 citra Sasab, dan 25 citra gunung beradu dari total 75 kain latih. Akurasi terbaik dihitung berdasarkan citra yang teridentifikasi dari seluruh percobaan.

Tabel 4. Hasil Akurasi dan Waktu Komputasi

\begin{tabular}{ccc}
\hline Percobaan & Akurasi & Waktu Komputasi (per detik) \\
\hline 1 & $96 \%$ & 17.4 \\
2 & $96 \%$ & 18.5 \\
3 & $85 \%$ & 21.2 \\
\hline
\end{tabular}




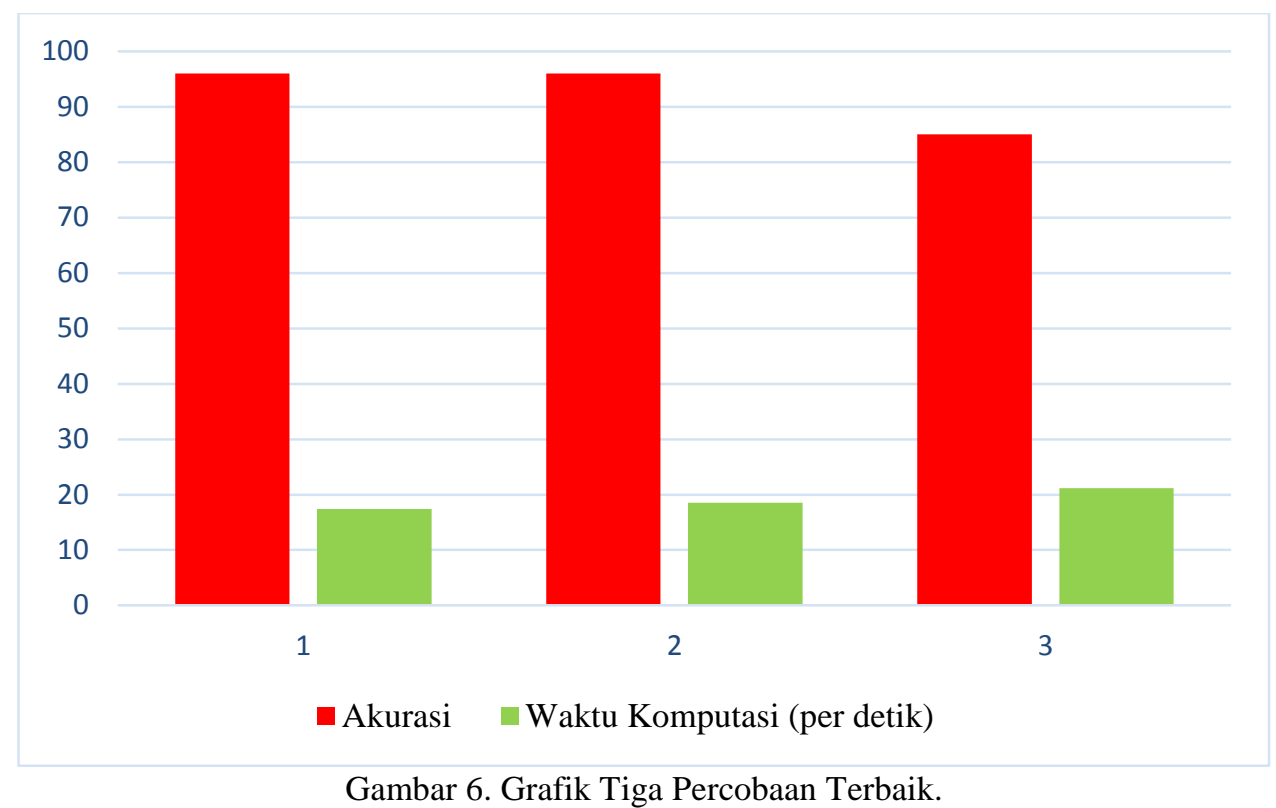

\section{KESIMPULAN}

Penelitian identifikasi kain tapis dengan menggunakan ekstraksi fitur Gabor filter dan klasifikasi Probability Neural Network (PNN) dapat diambil kesimpulan bahwa Implementasi penelitian dalam mengidentifikasi kain tapis dengan menggunakan ekstraksi fitur Gabor filter dan klasifikasi Probability Neural Network (PNN) didapati akurasi terbaik yaitu mencapai 96\%. Metode yang digunakan dan juga pengolahan terhadap objek citra Kain Tapis sangat mempengaruhi proses identifikasi pada penelitian ini. Penelitian ini juga memberitahukan pengetahuan kepada masyarakat pentingnya sistem komputerisasi pada era sekarang ini.

\section{DAFTAR PUSTAKA}

[1] N. D. Ariani dan K. Roisah, "Upaya Pemerintah Dalam Melindungi Kain Tapis dan Siger Lampung Sebagai Ekspresi Budaya Tradisional," Journal Law Reform, FH Universitas Diponegoro, Vol. 12, No. 1, pp. 73-86, 2016.

[2] V. N. Sagita, "Kain Tapis Sebagai Simbol Kekhasan Lampung," Journal Stipram Yogyakarta, Vol. 1, No. 1, pp. 1-10, 2018.

[3] S. Susiana, "Motif Kain Tapis Pada Kerajinan Tradisional Adat Lampung dalam Perspektif Etnomatematika Sebagai Kekayaan Matematika dan Budaya," Universitas Islam Negri Raden Intan Lampung, 2017.

[4] R. A. Rosanta dan R. E. Rizkiantono, "Perancangan Buku Visual Tapis Lampung sebagai Media Pelestarian Tapis," Jurnal Desain IDEA Institut Teknologi Sepuluh Nopember Surabaya, Vol. 17, No. 1, pp. 5-10, 2018.

[5] A. R. Putri, "Pengolahan Citra dengan Menggunakan WEB CAM pada Kendaraan Bergerak di Jalan Raya," Jurnal Ilmiah Penelitian dan Pembelajaran Informatika (JIPI), Vol. 1, No. 01, pp. 1-6, 2016. 
[6] S. R. Sulistyanti, F. A. Setyawan, dan M. Komarudin, Pengolahan Citra Digital dan Contoh Penerapannya, Edisi Pertama. Yogyakarta: Teknosain, 2016.

[7] A. Wijayono dan V. Putra, Penerapan Teknologi Pengolah Citra Digital dan Komputasi Pada Pengukuran dan Pengujian Berbagai Parameter Benang, Vol. 1. CV Mulia Jaya, 2017.

[8] D. Gabor, "Theory of Communication," Journal of the Institution of Electrical Engineers - Part III: Radio and Communication Engineering, Vol. 93, No. 26, pp. 429-441, 1946.

[9] Y. Wicaksono dan R. Wahono, "Color and Texture Feature Extraction Using Gabor Filter - Local Binary Patterns for Image Segmentation with Fuzzy C-Means," Journal of Intelligent Systems, Vol. 1, No. 1, pp. 15-21, 2015.

[10] R. Lim, "Verifikasi Personal Berdasarkan Citra Tangan dengan Metode Filter Gabor," Petra International Journal of Business Studies (IJBS), Vol. 1, pp. 1-10, 2004.

[11] L. Leonardo, "Penerapan Metode Filter Gabor Untuk Analisis Fitur Tekstur Citra Pada Kain Songket," Jurnal Sistem Komputer dan Informatika (JSON), Vol. 1, No. 2, pp. 120-124, 2020.

[12] L. Bai dan L. Shen, "A fast and Robust Gabor Feature Based Method for Face Recognition," in IEE International Symposium on Imaging for Crime Detection and Prevention (ICDP), 2005, pp. 95-98.

[13] J. Jing, X. Fan, dan P. Li, "Automated fabric defect detection based on multiple Gabor filters and KPCA," International Journal of Multimedia and Ubiquitous Engineering, Vol. 11, No. 6, pp. $93-$ 106, 2016.

[14] B. Kurniawan, R. M, dan M. Nasrun, "Implementasi Metode Gabor Dan Jaringan Syaraf Tiruan Pada Sistem Pengenalan Wajah," e-Proceedings of Engineering, Vol. 2, No. 2, 2015.

[15] D. F. Specht, "Probabilistic Neural Networks," Neural Networks, Vol. 3, No. 1, pp. 109-118, 1990.

[16] Y. Herdiyeni, "Mobile Application for Indonesian Medicinal Plants Identification Using Fuzzy Local Binary Pattern and Fuzzy Color Histogram," Proceeding of International Conference on Advanced Computer Science and Information Systems (ICACSIS), Vol. 1, 2012.

[17] H. Suhartanto dan Herry, "Algoritma Parallel Supervised PNN Structure Determination dan Implementasi Berbasis Message Passing Interface," Jurnal Ilmu Komputer dan Informasi Fakultas Ilmu Komputer Universitas Indonesia, Vol. 2, No. 1, p. 10, 2009.

[18] I. M. M. El Emary dan S. Ramakrishnan, "On The Application of Various Probabilistic Neural Networks in Solving Different Pattern Classification Problems," World Applied Sciences Journal, Vol. 4, No. 6, pp. 772-780, 2008.

[19] A. Hasnat, A. Ghosh, A. Khatun, dan S. Halder, "Pattern Classification of Fabric Defects Using A Probabilistic Neural Network and Its Hardware Implementation Using The Field Programmable Gate Array System," Fibres and Textiles in Eastern Europe, Vol. 25, No. 1, pp. 42-48, 2017.

[20] M. E. Abdulmunem dan F. B. Ibrahim, "Design of an Efficient Face Recognition Algorithm Based on Hybrid Method of Eigen Faces and Gabor Filter," IRAQI Academic Scientific Journals, Vol. 57, No.

3, pp. 2102-2110, 2016. 